\title{
Correspondence
}

\section{Ossification into the osteo-nevus of Nanta: an interpretative insight}

Osteo-nevus of Nanta is a rare and peculiar skin lesion histologically characterized by foci of osseous metaplasia within the dermal component of a benign melanocytic nevus. ${ }^{1}$ Osteo-nevi have been mainly encountered on the head and neck, in older patients, mostly women, ${ }^{2,3}$ although recently a near-equal frequency in male and female patients has been described. ${ }^{4}$ Here we report two cases of osteo-nevus and briefly discuss the histogenetic mechanisms behind the ossification in this melanocytic lesion.

A 70-year-old female patient presented with a dome-shaped cutaneous neoformation, maximum $6 \mathrm{~mm}$ in diameter, over her right brow ridge. Similarly, a 42-year-old male patient presented with a faintly brownish papular skin lesion over his forehead, measuring $8 \times 5 \mathrm{~mm}$, with no symptomatology of itching and bleeding. The lesions were surgically excised, and the tissues underwent histological examination, revealing a benign pigmented intradermal melanocytic nevus without evidence of dysplastic changes or malignancy. Just beneath the nevus, in the lower dermis, focal osseous metaplasia was observable, consisting of lamellar bone with fatty marrow at the center (Figs. 1 and 2), so a diagnosis of osseous metaplasia in an intradermal melanocytic nevus (osteo-nevus of Nanta) was made for both cases.

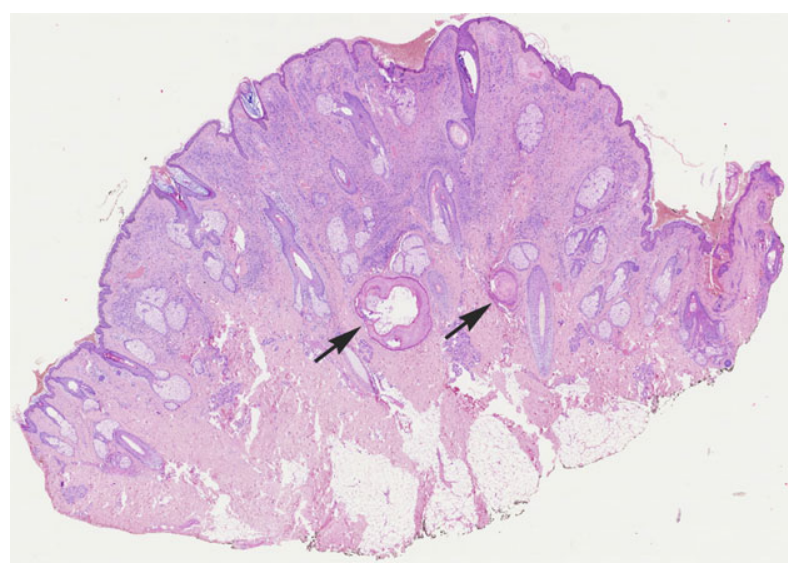

Figure 1 Photomicrograph captured by a digital slide scanning system (Leica Aperio LV1). Benign intradermal nevus showing two foci of osseous metaplasia (arrows) in the dermis beneath the nevus cell nests (hematoxylin and eosin stain; $\times 1,25$ magnification)
To date, the origin of secondary ossification within osteonevus of Nanta has not been precisely understood and is still debated. A few mechanisms have been proposed to justify this intriguing histopathological finding: (i) effect of estrogens on osteoblasts, resulting in cytokines release and bone tissue formation, in order to explain the formerly observed higher incidence in females; ${ }^{3}$ (ii) differentiation of fibroblasts with subsequent bone formation; ${ }^{5}$ (iii) evidence of the involvement of transforming growth factor- $\beta$ (TGF- $\beta$ ) and connective tissue growth factor (CTGF); ${ }^{6}$ (iv) age-related stromal changes conducing to bone metaplasia, accounting for the higher incidence of osteo-nevus in adulthood; ${ }^{4}$ and ( $v$ ) inflammation and rupture of a follicular cyst resulting in ossification. ${ }^{1}$ Nevertheless, none of these theories has reached strong consensus, and some questions have arisen. For instance, is it reasonable to think that osteo-nevus goes through ossification and calcification since it is adjacent to an injured and inflamed follicle? It could sound reductive and if so, we should have to observe many more osteo-nevi associated with follicular cysts. Challenging the perceived theories, here we would like to share our thoughts about an alternative histogenetic interpretation of the metaplastic ossification into osteo-nevus of Nanta.

It is known that, from the neural crest, a cellular heterogeneity arises including melanocytic, Schwannian, neuronal, neuroendocrine, epithelial, muscle, and connective cell lineages. ${ }^{7}$ Precursor cells from the cephalic neural crest, as well as giving rise to melanocytes residing in the skin of the head and face, form the facial and visceral skeleton. With regard to melanocytic lesions, histologic evidence of multidirectional differentiation includes common melanocytic nevi showing peripheral nerve sheath differentiation, adipocytic, or osseous metaplasia, cellular blue nevi with nerve fascicle-like structures, and melanomas showing desmoplastic or neurotropic phenotypes, depending on the regulation of multiple genes common to the neural crest cells and leading to distinct differentiation. In particular, the expression pattern of Hox genes in the cephalic neural crest seems to be implicated in the development of the head and facial skeletal tissue. ${ }^{8}$ It can be speculated that a dysregulation of gene expression can result in ectopic ossification, supporting the possibility that a common melanocytic nevus can show a region of bone formation, and explaining its infrequent occurrence. These findings are consistent with Cramer's "dermal precursor model" of melanocytic origin, where melanocytic differentiation starts with melanocytic precursor cells originating from the neural crest, their migration along peripheral nerves through the developing dermis and, eventually, their insertion into epidermis and hair follicles. ${ }^{9}$ In adulthood, when the neural 

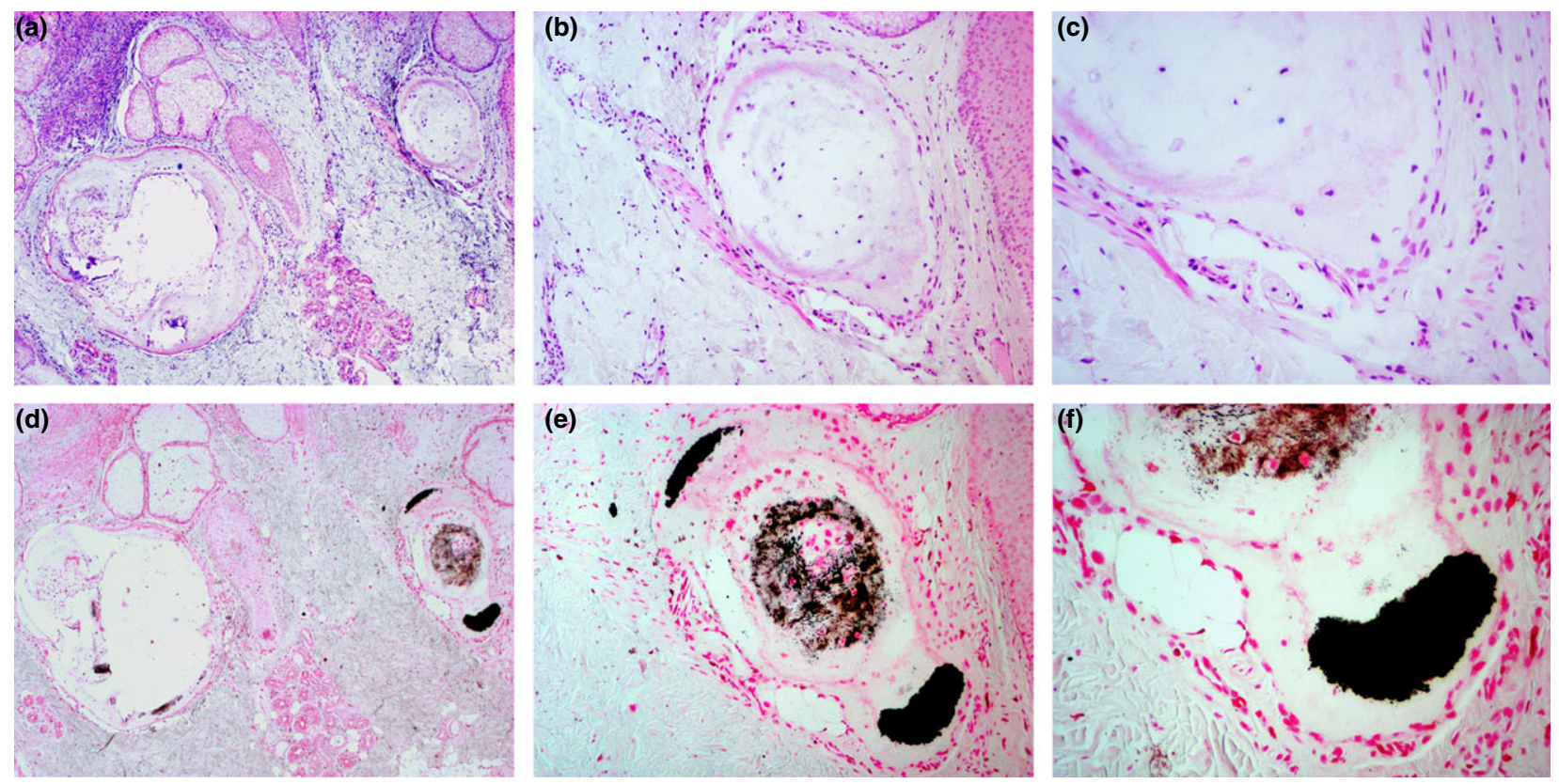

Figure 2 Photomicrographs taken by a light microscope (Zeiss Axioplan 2). Osseous regions of the osteo-nevus, stained with hematoxylin and eosin $(a-c)$ and von Kossa's method for calcification $(d-f)$, are shown at different magnifications $(a, d, \times 4$ magnification; b, e, $\times 10$ magnification; $c, f, \times 20$ magnification)

crest is no longer present, multipotent stem cells from the bulge of hair follicles can differentiate into melanocytes and many other cell types including neurons, myofibroblasts, bone, cartilage, adipose, glial, and smooth muscle cells. ${ }^{10}$ At the same time, melanocyte precursors seem to be implicated in nevogenesis, upon activation of specific mutations. Consistent with the stem cell-based concept of nevogenesis and the neural crest stem cells' multipotentiality, why not consider that the occurrence of ossification into the osteo-nevus of Nanta may be explained by the multidirectional differentiation of a common precursor cell, originating from the cephalic neural crest, into both facial melanocytes and osteocytes? This interpretation could thus expand the current views on the histogenetic mechanisms behind this melanocytic lesion, and then further experimental studies will help to thoroughly explore and confirm the hypotheses about its pathogenesis.

$$
\begin{array}{r}
\text { Daniela Murtas }^{1, *}, \mathrm{PhD} \\
\text { Franco Rongioletti }^{2}, \mathrm{MD} \\
\text { Caterina Ferreli }^{2}, \mathrm{MD} \\
\text { Laura Atzori }^{2}, \mathrm{MD} \\
\text { Luca Pilloni }^{3, * *}{ }^{2}, \mathrm{MD}
\end{array}
$$

${ }^{1}$ Department of Biomedical Sciences, Section of Cytomorphology, University of Cagliari, Cagliari, Italy

${ }^{2}$ Department of Medical Sciences and Public Health, Section of Dermatology, University of Cagliari, Cagliari, Italy

\author{
${ }^{3}$ Department of Surgical Sciences, Section of Pathology, \\ University of Cagliari, Cagliari, Italy \\ *E-mail: murtas@unica.it \\ **E-mail: lucpilloni@tiscali.it
}

Funding: Fondo Integrativo per la Ricerca (FIR), University of Cagliari.

Conflicts of interest: None.

doi: $10.1111 / \mathrm{ijd} .14280$

\section{References}

1 Massi G, LeBoit PE. Variants of common nevus. In: Massi G, LeBoit $\mathrm{PE}$, eds. Histological Diagnosis of Nevi and Melanoma, 2nd edn. Heidelberg: Springer-Verlag Berlin Heidelberg, 2014: 47-76.

2 Al-Daraji W. Osteo-nevus of Nanta osseous metaplasia in a benign intradermal melanocytic nevus: an uncommon phenomenon. Dermatol Online J 2007; 13: 16.

3 Conlin PA, Jimenez-Quintero LP, Rapini RP. Osteomas of the skin revisited: a clinicopathologic review of 74 cases. $A m ~ J$ Dermatopathol 2002; 24: 479-483.

4 Bezić J, Karaman I, Zekić Tomaš S, et al. Osteonevus of Nanta revisited: clinicopathological features of 33 cases. $A m ~ J$ Dermatopathol 2016; 38: 859-861.

5 Lee YB, Lee KH, Park CJ. A case of intradermal melanocytic nevus with ossification (nevus of Nanta). Ann Dermatol 2008; 20: 197-199.

6 Keida T, Hayashi N, Kawakami M, et al. Transforming growth factor beta and connective tissue growth factor are involved in the evolution of nevus of Nanta. J Dermatol 2005; 32: 442-445. 
7 Achilleos A, Trainor PA. Neural crest stem cells: discovery, properties and potential for therapy. Cell Res 2012; 22: 288304.

8 Le Douarin NM, Creuzet S, Couly G, et al. Neural crest cell plasticity and its limits. Development 2004; 131: 4637-4650.

9 Grichnik JM, Ross AL, Schneider SL, et al. How, and from which cell sources, do nevi really develop? Exp Dermatol 2014; 23: 310-313.

10 Kinsler VA, Anderson G, Latimer B, et al. Immunohistochemical and ultrastructural features of congenital melanocytic naevus cells support a stem-cell phenotype. Br J Dermatol 2013; 169: 374-383.

\section{Supporting information}

Additional Supporting Information may be found in the online version of this article:

Figure S1 Photomicrographs taken by a light microscope (Zeiss Axioplan 2). Osseous regions of the osteo-nevus, stained with hematoxylin and eosin $(\mathrm{a}-\mathrm{d})$ and von Kossa's method for calcification $(\mathrm{e}-\mathrm{h})$, are shown at different magnifications $(\mathrm{a}, \mathrm{e}, \times 1,25$ magnification; b, f, $\times 2,5$ magnification; $c, g, \times 4$ magnification; $\mathrm{d}, \mathrm{h}, \times 10$ magnification). 
(a)

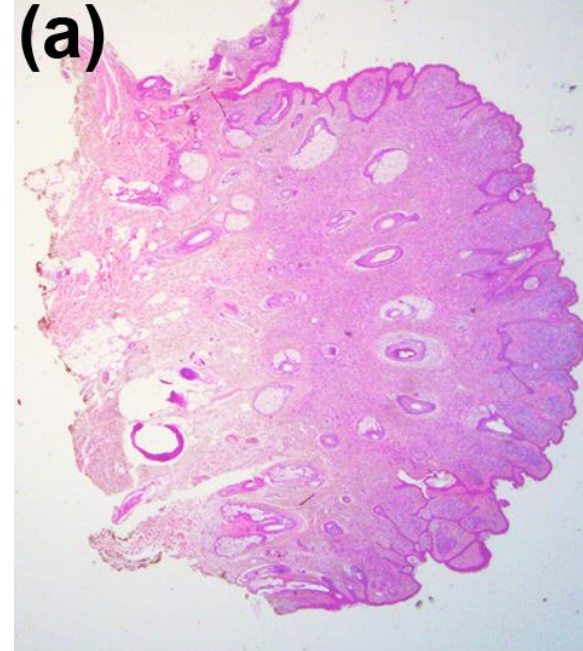

(e)

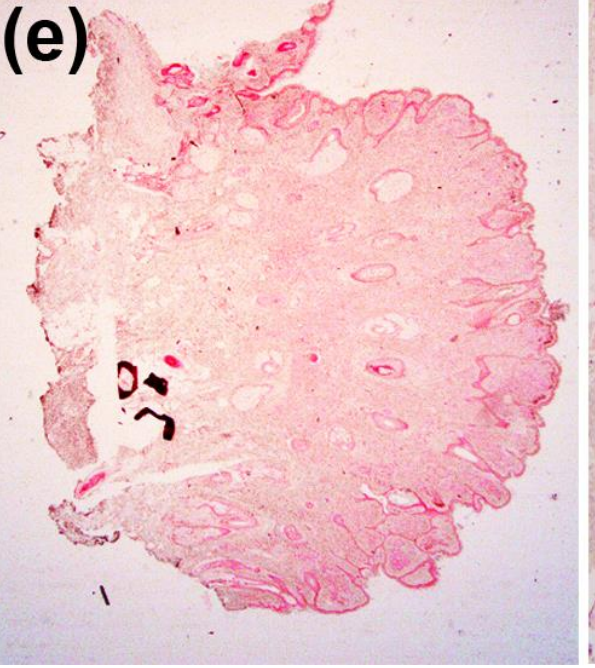

(b)

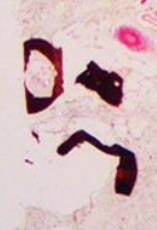

(f)

Figure S1 Photomicrographs taken by a light microscope (Zeiss Axioplan 2).

Osseous regions of the osteo-nevus, stained with hematoxylin and eosin (a-d) and von Kossa's method for calcification (e-h), are shown at different magnifications

$(a, e, \times 1,25$ magnification; $b, f, \times 2,5$ magnification; $c, g, \times 4$ magnification; $d, h, \times 10$ magnification).

(d)

(h)
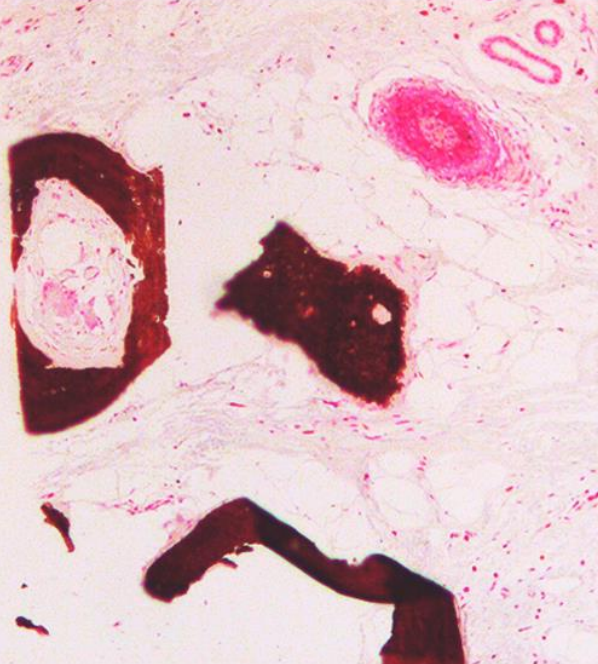

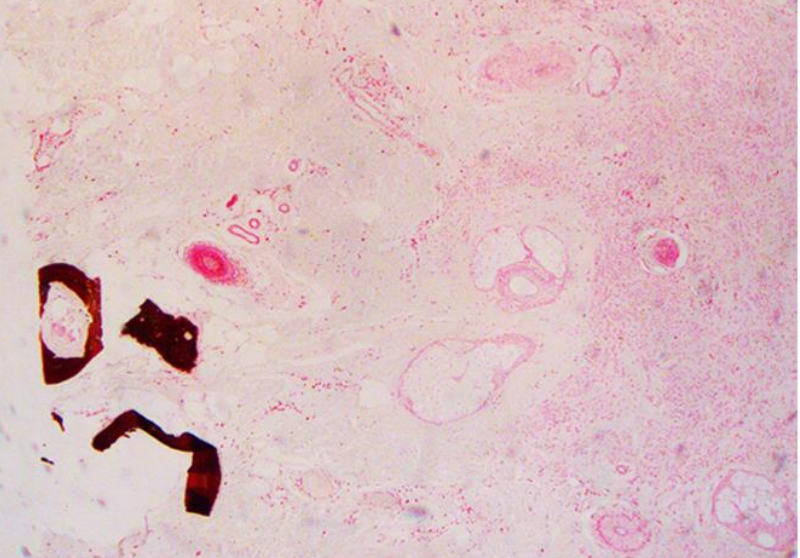

(g)
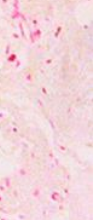